\title{
Engaging Communities in the Hard Quest for Consensus
}

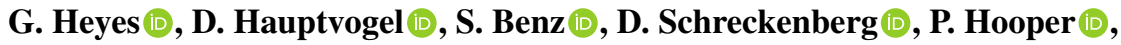 \\ and R. Aalmoes $(\mathbb{D}$
}

\begin{abstract}
Mistrust, negative attitudes and the expectation of not having any voice against airport authorities can considerably impact on the perception of aircraft noise exposure, lead to increased annoyance and can even influence sleep quality of the noise affected residents. As a result, quality of life can reasonably be assumed to be reduced. This chapter focuses on measures to engage airport communities in aviation-related decision making by improving the information and communication of airports in order to enhance residents' 'competence' and also trust in the airport noise authorities. The role of non-acoustical factors, including aviation-related media coverage in this process, is discussed and results from a media coverage analysis conducted in the ANIMA project are presented. Based on research on perceived fairness in communication, recommendations are given as to how to communicate and engage residents with the aim of building a neighbourly relationship between airport authorities and residents on an even footing and, thus, enable an improved exchange leading to deeper understanding and comprehension by both parties. Results from the ANIMA review on airport management strategies (including communication and engagement aspects) of several European airports are presented and conclusions are drawn about what characterises good (or bad) communication and community
\end{abstract}

Explaining successful methods employed to engaged communities and the prerequisite for such success

G. Heyes $(\bowtie) \cdot$ P. Hooper

Ecology and Environment Research Centre, Department of Natural Sciences, Manchester

Metropolitan University, Chester Street, Manchester M1 5GD, UK

e-mail: g.heyes@mmu.ac.uk

D. Hauptvogel

Sleep and Human Factors Research, Institute of Aerospace Medicine, German Aerospace Center (DLR e.V.), Linder Höhe, 51147 Cologne, Germany

S. Benz $\cdot$ D. Schreckenberg

ZEUS GmbH, Centre for Applied Psychology, Environmental and Social Research, Sennbrink 46, 58093 Hagen, Germany

R. Aalmoes

Royal Netherlands Aerospace Centre NLR, Anthony Fokkerweg 2, 1059 CM Amsterdam,

Netherlands 
engagement strategies for the purpose of a neighbourly relationship between the airport and its residents.

Keywords Communication $\cdot$ Engagement $\cdot$ Non-acoustic factors $\cdot$ Fairness Evaluation $\cdot$ Noise management

\section{Introduction}

Aircraft noise has been shown to cause adverse effects on human health (see Chapter 7). It is assumed that this is partly mediated by the effect of annoyance. Previous chapters have taught us the important role of non-acoustic factors for the levels of annoyance.

As described in Chapter 8 there are different non-acoustical factors, i.e., situational and personal/social factors that contribute to how noise is perceived and processed, and that these non-acoustic factors can affect the impact of environmental hazards. Non-acoustical factors can be summarised as factors that are not directly connected to the sound [1], but modify or co-determine the response to it. In this way managing non-acoustical factors can be seen as a crucial and essential opportunity to minimise annoyance reactions and reduce the adverse effects of noise. This is also due to the fact that noise reduction alone has not resulted in corresponding reductions in annoyance. Hence, non-acoustic factors are seen as having a critical impact on noise effects, and are equally important to consider when tackling annoyance and other noise responses. In Chapter 8, several categories of non-acoustical factors were identified, some of which can be more influenced than others, with some especially important. One's general sensitivity to noise, personal (mis-)trust in responsible authorities, attitudes towards the airport and aviation in general as well as expectations and fears, e.g., for health risks and aircraft crashes, have been identified as the most important nonacoustic factors. Besides these factors, socially shared information is also relevant for how we perceive or what we experience [2]. Particularly vital and influential factors are those related to communication and social exchange. Communicating with other people about issues informs our knowledge and shapes our expectations. For example, a neighbour complaining about something can directly affect how we perceive the topic of complaint.

By studying the influence of discourse on people's experience of aircraft noise, research provides evidence that the discourse in an airport region not only originates the degree of annoyance but also how policy discourse resonates in private discourses $[3,4]$. One finding was that people are influenced by policy in that they refer to policies when talking about noise experience. Private discourse often directly reflects the story lines of annoyance policies. This was shown by comparing two airport regions, Amsterdam Schiphol and Zurich Kloten. Further, it seems that noise experience was influenced by the discourse in that annoyance ratings were supported by policy discourse arguments. Taken together this can mean that when people are engaged 
in the process of policy definition it can contribute positively to their experience of noise.

\section{The Role of Media Coverage}

Another factor able to contribute to the impacts of noise is public discussion and how the media reports noise. One could summarise it by saying that dominant policy discourses can shape our experience [4], which suggests that media coverage is at least able to shape our experience and perception of noise. Interest of the media focuses on coverage on deviating opinions and events, such as demonstrations, not on activities that influence existing practices.

Findings from research on other sources of environmental exposures suggest that the way the media frames information in its reports shapes the expectations of people around the exposure source. Moreover, expectations around possible adverse health outcomes of exposure sources can contribute to the occurrence of negative health outcomes [5], which has shown that the framing of information influences how participants perceive the noise. Studies on wind turbine noise for example suggest that when participants saw negative framed material on the effects of infrasound it affected the number and intensity of health complaints people reported when exposed to [6] or annoyed by [7] infrasound. The same was true for a group that were shown positive information about infrasound, they reported less health complaints and even some positive effects while exposed to infrasound. It is assumed that media coverage about potential adverse health effects builds up expectations on the consequences of the exposure and this, for various reasons, increases or even causes potential health outcomes.

As highlighted in Chapter 8, the perception of avoidability, unpredictability, uncontrollability, and procedural unfairness increases stress responses and annoyance, and reduces the perception of being able to cope. In particular, when the exposure situation is likely to change, e.g. due to re-allocation of flight paths, increase in air traffic, and/or an expansion of the airport, questions arise from new or increasingly exposed residents, such as: Are these changes necessary or could they be avoided? Is the new situation predictable? Are the changes in exposure fair and are the way these changes are established and the decisions made fair? Information is essential in residents having answers to these questions, and thus having some form of perceived control of the situation. This is particularly the case in ambiguous situations where residents already dislike situations, and are expected to dislike future situations. Hence, this is where socially shared information such as from the media comes into play. Another point in line with this is that it facilitates the adoption of an attitude, intention, or behaviour, if this follows a social norm, that is, if relevant persons (family, neighbours, friends) expect such an attitude, intention, or behavior from someone [8]. If family members or neighbours are annoyed by aircraft noise, it is easier to be annoyed too, or to regard this as confirmation of one's own annoyance (in terms of 'I am not alone with my annoyance'). In addition, other people talking 
about noise issues can raise awareness or draw attention to a noise issue. The latter has become particularly relevant in the era of the internet and social-media in which the networks or individuals, be them formal or informal, have extended significantly. Social-media in particular enables one's views to be potentially influenced by a large number of people who may not be experts on a subject but who nonetheless can play an informing role in the development of an individual's perceptions on a given subject (the role of social media is discussed in more detail in Chapter 10).

The role of media, in particular local media, is not so much that it produces noise responses such as annoyance, but that it can reflect socially shared knowledge, opinions, and perceptions of noise which particularly become relevant in situations of change. In this sense, it is hypothesised that the way aircraft noise is covered in media articles influences the way that noise exposure is perceived and processed, e.g. resulting in expectations and contributing to noise annoyance and further health issues.

Analysis of media reports showed that the motivation for participation in the NORAH study around Frankfurt Airport was influenced by media coverage about Frankfurt Airport: a higher number of reports about the study were related to a higher number of completed interviews in the study (Guski, Peschel, Wothge, 2014). This indicates that the media articles seem to have contributed to the residents' awareness of the importance of the study and that it would be useful perhaps even for one's own residential quality of life to participate-in terms of "if the study is on health effects of aircraft noise and repeatedly described in the media, it has a point there and I should be part of it'.

\section{Results of the ANIMA Media Coverage Analysis}

The media analysis conducted within ANIMA deals with how media reports about aircraft noise and how related topics may influence annoyance ratings assessed in the NORAH study on health effects of aircraft noise.

This was done by linking media reports around Frankfurt Airport during the NORAH study to the annoyance ratings over the same time periods and examining if annoyance ratings are influenced by media reports. Looking at the content of news reports headlines, categories of topics were derived from the reports, such as "night flight", "noise exposure","protest", among others, and analyses were conducted to find out how reports with certain content may affect the annoyance ratings. For each participant, reports from 180 days prior to the study interviews were taken into account as it was assumed that some time was needed to process media reports and assimilate information.

First results indicate that media coverage about certain noise-related topics have an impact on annoyance ratings, in that stronger annoyance has been reported when media articles more frequently reported about these noise-related topics (for further details see Hauptvogel et al., 2021). 
First and foremost, the focus of most media is reporting about existing issues and to shed light on problems that are relevant and/or pending. It is about displaying and focusing attention on e.g. local noise issues around an airport. The frequency of reporting about certain topics reflects the relevance of these topics.

So when it is assumed that annoyance ratings can partly be explained by media reports, it is not based on the assumption that reporting explains the annoyance but that media coverage can have an impact on how exposures are perceived and to be aware of how framing of certain health issues are delivered. Media reporting can have an effect itself in providing attention to the specific problem. When airports or other authorities work on improvements to the problem, media coverage adapts accordingly. Media coverage can therefore cause but also extend existing discourse about the topic, which in turn shapes opinions and can influence the perception of the noise itself.

Therefore the focus of any intervention should not be to change information but to change the problem, which in turn changes the information about the change, topic or issue. This is a dynamic process. Thus, when communication and engagement measures are trying to determine the discourse in the region around the topic itself, this cannot be simply confined to changing the communication around it but to include interventions that focus on reduction of noise. In other words, meaningful communication and engagement is that relating to the reduction of the causes of negative impacts.

Change of communication and engagement strategy of an airport has to be accompanied by technical or operational changes and vice versa. Communication without implementing changes may even encourage higher mistrust in responsible authorities. The whole dynamic has its origin in the problem, the noise source, itself and how it is managed.

Transferring this to the Balanced Approach could mean that communication and engagement has to be built across all four pillars.

\section{Communication and Engagement and Noise Management}

Given the nature of the described non-acoustical factors, including media coverage, it is hardly surprising that researchers and the aviation industry have identified communication and engagement as key elements in the management of noise impacts.

The aviation industry has gone to considerable effort to reduce noise and noise impact over the past 50 years, mostly via significant reductions in noise from individual aircraft, driven by increasingly stringent certification regulations regarding aircraft design. These reductions have not, however, resulted in corresponding reductions in annoyance. Instead, public opinion is an increasing constraint to airport activity, despite fewer people being exposed to higher levels of noise than in previous years [9]. The ICAO Balanced Approach has looked to help address this by not just reducing noise at source (although this remains important), but also through other measures that are designed to better manage noise for the benefits of residents. As well 
as encouraging reductions in noise at source, the Balanced Approach also outlines actions that can be taken with regard to: land-use planning and management policies that seek to reduce noise exposure on the ground, either by keeping noise sensitive developments (i.e. conurbations) away from high-noise areas, or by managing sound on the ground, through insulation programmes, Operational Procedures, such as moving flight tracks so as to not over fly communities, and; operating restrictions, for instance night flight limits or absolute caps on aircraft movements.

And, finally, in 2007 the Balanced Approach Guidance was expanded to include 'People issues'. This added fifth pillar focuses on communication strategies, advocating the use of enhanced information that is easily accessible by the public and emphasises the role of consultation. Although not formally adopted through the Balanced Approach as a core pillar, the concept of communication and engagement as a noise management tool is now seen to be increasingly important.

Communication and engagement does not purely exist as an additional pillar through which noise can be managed - it can also help aid the successful implementation of other balanced approach measures. Successful noise management actions must be technically feasible or viable in order to be implemented, and together with a range of technical data, the industry has typically focused the development of Balanced Approach interventions on such data in order to develop interventions that are deemed to have the greatest potential impact and benefit for noise affected communities. Indeed, national noise policy is often focused on such considerations, leading airports to develop, for instance, new operational procedures based on aggregated noise metrics and success criteria such as the number of people exposed to certain levels of noise. This is a sensible approach, which can provide airports with confidence that the noise management actions they develop will be more likely to result in positive outcomes. As previously mentioned however, improvements in noise as measured through such approaches is not a guarantee that residents will perceive them as successful, or that there will be a positive impact on annoyance and complaints. The reason for this is that truly successful noise management interventions require a further consideration to technical feasibility and viability-desirability. Put simply, if a noise management intervention looks good on paper, but is not deemed to be effective or desirable in the eyes of those it is designed to serve (i.e. residents), then it is less likely to be perceived by those same residents as being an effective or appropriate response to the noise they experience. Through communication and engagement, airports are able to explain noise and noise management processes to residents, but also gain their feedback and insight into what success looks like in residents' own eyes. This information can be incorporated into decision making and help to produce noise outcomes that are more likely to be viewed as appropriate. 


\section{Why is Fairness so Important in this Context?}

The operation of an airport inevitably leads to noise. Unfortunately and despite the application of the four "traditional" pillars of the ICAO Balanced Approach, it cannot be ruled out that the noise affects some people more than others. The nature of aircraft noise means that it has to be distributed in a certain way over parts of the population.

Logically, this distribution is inherently unfair-as some people get more noise than others. Aircraft noise is man-made and the exposure to it is often seen as a social conflict arising from the fact that residents view noise as the airport exposing them [10]. In order to come to a certain distribution of the noise, decisions have to be made. Procedures have to be applied to reach these decisions and the results of the decision-making process need to be communicated to affected people. For this reason, it makes sense to look at the exposure to aircraft noise from the perspective of fairness research, in particular research on procedural and interpersonal fairness, which offer some important starting points on how to deal with this inherently unequal distribution.

\section{Fairness as the Overall Goal}

An observation made since the 1970 s is that people are more likely to accept and adopt unfavourable outcomes of decisions when the decisions are based on correct information, when the decision-making process is free from bias and applied consistently over time and, above all, when the affected people have been involved in the decision-making process [11]. This so-called "fair process effect" is based on the observation that giving people "voice" makes them more likely to accept decisions [12-14]. As described in detail in Chapter 8, noise annoyance is a stress response that depends on various factors such as how much coping opportunities and resources people perceive.

In evolutionary terms, procedural fairness is an extremely important indicator for a person to be an accepted and valued member of a group. It therefore fulfils the need for belonging and self-esteem [12, 14].

This means that airport management should apply procedures that are as fair as possible and recognised as such by the public. The assumption that giving voice leads to increased perceived fairness and reduced annoyance due to noise exposure has already been shown in studies [15] when people who could express their preference for a certain sound were significantly less annoyed than people who could not. However, annoyance was particularly high among people whose preference was actively ignored. A more recent study [16] also showed that many opportunities to participate led to a higher acceptance of a fictitious airport expansion. It also showed that the focus on the jobs created by the airport expansion had no effect on acceptance.

In sum, it can be said that procedural aspects of aircraft noise distribution have an enormous influence on how people perceive aviation, the airport and the noise and 
to what extent they are annoyed by the noise. Interventions that take these insights into account can therefore be very effective.

Despite the positive effect of having voice or control in the decision-making process, fairness research has also shown the critical impact of providing information and justification of a decision for the perception of the outcome of this decision. From the perspective fairness regarding informational aspects and regarding the interaction between two parties (so-called informational and interpersonal fairness), people may perceive unfairness, even though they consider the procedure and its result as fair, just because of an improper treatment or a lack of justification by the decisionmaker [17]. But also in case of a negative outcome, the decision process may be recognised as fairer when an adequate justification or causal account is given by the authority who made the decision $[18,19]$. These findings point to the need for a good communication strategy of the airport management and we will come back to the lessons learned from this branch of fairness research when we define criteria for good communication and information.

To give an overview, research has identified a set of criteria and standards relating to the fairness aspects mentioned above, which, taken together, can create a perception of fair process and fair interaction with the parties concerned. Research distinguishes between several facets of fairness. A distinction can be made between procedural, interpersonal and informational fairness. All of these main fairness standards comprise a number of criteria:

\begin{tabular}{l|l|l}
\hline \multirow{2}{*}{ Procedural } & Fairness standards & \\
\cline { 2 - 3 } & Process control & procedures provide opportunities for voice \\
\cline { 2 - 3 } & Decision control & procedures provide influence over outcome \\
\cline { 2 - 3 } & Bias suppression & procedures are neutral and unbiased \\
\cline { 2 - 3 } & Representativeness & procedures take into account concerns of subgroups \\
\cline { 2 - 3 } & Consistency & procedures are consistent across persons and time \\
\cline { 2 - 3 } & Accuracy & procedures are based on accurate information \\
\cline { 2 - 3 } & Correctability & procedures offer opportunities for appeals of outcomes \\
\hline \multirow{2}{*}{ Informational } & Truthfulness & explanations about procedures are honest \\
\cline { 2 - 3 } & Justification & explanations about procedures are thorough \\
\hline Interpersonal & Propriety & enactment of procedures refrains from improper remarks \\
\cline { 2 - 3 } & Respect & enactment of procedures refrain from improper remarks \\
\hline
\end{tabular}

(Rules taken from [11, 13, 20, 21], after [22], Colquitt)

With these research-derived criteria, concrete recommendations can be derived on what constitutes good communication and engagement and how to build a neighbourly relationship with residents of local airport communities. 


\section{What is Communication and Engagement}

At its core, communication refers to the dissemination of information from one person or organisation, to another person or organisation. For instance, governments may communicate information about certain changes to legislation, or about new laws or policies to the public_-government health and safety warnings around the time of the Covid-19 pandemic being a good example. For aviation, airports may communicate for a range of reasons, for example sharing noise data or operational changes to their communities, or performing marketing activities regarding things like the promotion of noise management measures, reductions in noise levels as described through metrics such as $\mathrm{L}_{\mathrm{den}}$, or quality of life benefits afforded to residents as a result of airport activity as well as contributions to the national or regional economy. What really defines communication however is the one-way flow of information that it typically implies. That is, one actor passing on information to another. Typically, communication tools therefore include things like newspaper articles, radio advertisements, websites, mail and other printed media such as noise action plans, noise contour maps or other corporate reporting-with more recent innovations including the use of social media to, for example, communicate things like airport operating conditions. The intent of such activities is for a specific message, or messages, to be heard by a target audience, at a specific point in time, and with a targeted outcome. As such communication activities tend to lose meaning over time, and whilst their oneway flow of information and generic targeting can be helpful in explaining things to residents, they can also lead to disengagement from receptive audiences or confusion if messages are unclear, misunderstood or not trusted. This is particularly difficult for airports, who are tasked with explaining highly complicated, multi-faceted and technical data in simple and easily digestible formats. This is a significant challenge as simple communication measures can lack relevant information, whilst communication materials that show a range of information can be critiqued for being too complicated to understand. This is compounded by the fact that communicating noise through different metrics has a range of different advantages and disadvantages. Noise contours for example, do a good job at illustrating aggregated noise levels around an airport, however they fundamentally describe an audible factor, through a visual medium, and describe noise in a way that is not experienced by residents, who live through individual noise events. The result is that contour maps are often poorly understood by residents [23], despite legislation such as the Environmental Noise [24]/49/EC requiring airports to produce such contour maps and to disseminate them to the public. In worst case scenarios poor communication can lead to mistrust between airports and community groups who may begin to question the information that they are being told, thus raising the question of the value of the communication itself.

Engagement, on the other hand, refers not just to the provision of information to stakeholders, but to establishing a dialogue. Here the objective is to embark on a conversation with stakeholders to explain things to them, but importantly, to also listen. The concept is rooted in the fact that residents are the experts on their own lived 
experiences and can offer important insight that may otherwise remain unknown, and that could play an important role in decision making around the development of any noise management interventions that are likely to be perceived as acceptable. Hence, the aim is not only to pass information onto stakeholders, but to also listen to stories about their lives, their fears, the things they do in life, and to build empathy for them and their perspectives on given issues. Put simply, engagement implies not just talking, but also listening, and understanding and the need to tailor messages and information to different people, in so doing having the potential to become more meaningful interactions over time. The importance of engagement can be seen through concepts such as design thinking, which are applied in organisational settings to develop solutions to a range of operational challenges. The process is based on the idea that considering the needs of a given beneficiary of a service is essential in order to maximise the likelihood of the success of that service. The process is rooted in deep engagement with stakeholders, including the use of multi-stakeholder design teams, collecting qualitative data to complement quantitative information, and understanding and addressing core challenges directly. Similar approaches are already set out in aviation noise through proposed processes in the United Kingdom's Civil Aviation Authority CAP 1616 [25] document and the United States Federal Aviation Authority Program 150 [26]. Both take iterative step processes to develop noise management interventions that include a focus on understanding resident needs and embed them as core principles in the development of noise management actions. Methods for engagement go beyond the mere dissemination of information as with pure communication, and involve more participatory methods such as consultation, focus groups, workshops or full collaborative and participative working groups. Hence communication and engagement can be seen as sitting on a spectrum, from the simple provision of information, through to more participatory levels that afford degrees of citizen empowerment through partnerships, delegation of control. This has been helpfully illustrated by [1], who, as illustrated in Table 1, created a Wheel

Table 1 Asensio el al. [1] types of public participation

\begin{tabular}{l|l}
\hline Category & Sub-Category \\
\hline Information & Minimal communication \\
\hline & Limited information \\
\hline Gonsultation & Lood quality information \\
\hline & Customer care \\
\hline Participation & Genuine consultation \\
\hline & Effective advisory body \\
\hline & Partnership \\
\hline Empowerment & Limited centralised decision making \\
\hline & Delegated control \\
\hline & Independent control \\
\hline & Entrusted control
\end{tabular}


of Participation for airport noise management, adapted from the work of Arnstein's Ladder of Public Participation [27] to illustrate the types of public participation that exist.

Communication tools may still be used as part of engagement, but rather than as the primary output, they merely lay the framework on which a wider discussion can take place. At the same time, it should be stressed that engagement with stakeholders does not imply that good levels of communication have taken place. It is entirely possible for example, that an airport may be seeking to engage with residents, but communicating noise information to them poorly, or even in a manner that residents deem to be dishonest (such claims may be untrue, but if they are true in the eyes of residents they remain a relevant management concern). Likewise, processes of engagement do not necessarily mean success. Engagement has to be meaningful and with an honest intent to listen to and learn from stakeholders. Failure to do this can result in mistrust, which once lost can be almost impossible to win back.

Building on findings from case study research conducted in ANIMA, some of the characteristics and key principles of, and differences between, communication and engagement are outlined below:

- Communication typically sets out to describe what is happening, or what has happened, or to perform basic consultation regarding a set of predetermined interventions. Engagement on the other hand, explains why things are happening, and seeks to obtain the input of stakeholders regarding decisions that have not yet been taken, the aim being to produce fair outcomes.

- Communication describes one way dialogues between airports, speaking to residents. This means that communication methods more often than not include contour maps, noise reporting, noise action plans, or marketing information. Engagement on the other hand describes two-way flows of information, and therefore utilises methods such as consultation events, workshops, focus groups and Dialogue Forums. These require more effort and resources to operate but better reflect a more engaged and informative process that is more likely to lead to outcomes that are perceived to be successful in the eyes of stakeholders.

- Communication typically uses quantitative data to describe and communicate noise. This is useful in that it is an attempt to describe noise in the most accurate way possible. However it is also beset with difficulties of describing a complex and highly technical concept (noise) through simple metrics. Engagement may also use the same information, but its two-way flow of information also concerns qualitative data, i.e. how residents feel about noise and how noise is likely to affect them.

- In pure communication, the actor that is leading the communication typically takes on the role of expert. This can lead to hierarchical stakeholder relationships that can make establishing trust difficult, and can cause the lead communicator to discount other sources of information. Engagement on the other hand is typically based on levelled hierarchies in which all stakeholders are seen to have potentially valuable information to offer decision making processes. Empathy plays a key role and consensus is deemed more likely to be reached through understanding. 
The above may suggest that engagement is a more comprehensive approach than communication, it should not be seen as necessarily being best practice in every scenario, as the level of engagement activity undertaken by an airport should be determined by the desired output of the interaction. Hence, both communication and engagement approaches should be used with an awareness of the attributes and benefits of each, and importantly, the circumstances surrounding the area in which they are to be implemented, for instance what is the ultimate desired outcome of the interaction, the understanding of which may itself require some form of engagement. That said, best practice dictates that engagement should at the least be considered whenever an airport is looking to communicate something to its residents, or to make operational changes or other modifications to airport activity. The importance of this can be appreciated through the fact that noise management, at its fundamental core, exists for the benefit of airport residents, be it due to direct pressure to manage noise as demanded by communities, or in response to legislation designed to protect noise affected communities from the potentially significant noise impact caused by noise exposure. It is therefore important to not just develop noise management actions or general airport operations that are technically feasible or viable, but to also consider what actions are desirable in the eyes of those residents.

\section{A Tale of Communication and Engagement Gone Wrong}

Vienna Airport is the largest airport in Austria and of major economic importance to the region. The airport built its second runway in 1972, however they projected that airport capacity would be reached by 2012 and that an additional runway would therefore be needed to continue airport growth.

Hence, the airport began plans for a third runway in 1998 to the south of existing airport infrastructure. However, the airport made such an announcement without effective consultation or dialogue with its communities.

The result was significant opposition to the runway by local community groups who felt aggrieved about the lack of consultation, and the health impacts that they would be subjected to from increased traffic, particularly for communities who would be newly overflown by aircraft arriving and departing from the new runway. By not being engaged with, trust was damaged and opposition campaigns proved so successful that approval for the third runway was not granted-indeed, some 20 years later, the runway has still not been built.

This is an example of an airport not engaging with its residents effectively, and demonstrated the potential impact to airport operations from doing so. However, Vienna Airport learned from this mistake, and as we demonstrate later in the chapter, they are now regarded as one of the best examples of an airport communicating and engaging with its residents. 


\section{How to Do 'Good' Communication and Engagement}

Noise managers increasingly understand the human response to noise and the role of non-acoustic factors in driving annoyance. Addressing such factors is however complicated, and coupled with external pressure for absolute reductions in noise, has seen the majority of noise management actions focus on addressing acoustic factors. Although such an approach is understandable, doing so has not always led to successful outcomes-hence why noise (as measured through metrics such as noise level equivalents) has remained stable or fallen at many airports, against a background of increased levels of reported annoyance.

Despite the continuing trend that communication and engagement are recognised by airports as important, there is a lack of clear recommendations on what constitutes successful communication, how to implement it and how to evaluate it. So what needs to be emphasised here is that any kind of communication and engagement should be underpinned by certain quality criteria and theoretical principles. For this purpose, we suggest focusing on principles derived from research on fairness in social exchanges. This is the only way to achieve a long-term and sustainable trust and acceptance of the airport. Great progress in the ANIMA Project was achieved since not only theoretical recommendations were derived but their application in practice was assessed as well. So how have airports been performing in terms of communication and engagement? This has been a key question throughout the ANIMA Project. Airports have been communicating about noise for many decades, with approaches moving over time from a purely dissemination of information approach, towards processes more aligned to consultation and engagement that can aid airport decision making.

In a review of airport case studies across the European Union, ANIMA research came to the following conclusions about communication and engagement:

- There has been an evolution from communication towards more participative forms of discourse, notably an increase in consultation and the development of noise dialogue or community programs.

- However, communication and engagement tends to happen in a relative ad-hoc manner with data provision often following guidance to produce quantitative noise data only, and with such data often being disseminated in ways that publics find hard to comprehend.

- Communication and engagement tends to remain largely about information provision rather than leveraging the potential benefits of engagement in light of the role of non-acoustic factors.

- Communication and engagement often happens without an intended outcome that seeks to address given challenges or needs.

- There is rarely any evaluation as to the impact of any communication and engagement.

- Communication and engagement is generally seen as ancillary noise management activities, rather than as playing a key informing role in the success of other interventions, or as a management tool in their own right. 
As with all aspects of noise management, it is important that airports do not follow prescribed advice based on 'best practices' from elsewhere, but rather base their actions on their own definitions of 'good practice' as appropriate for their own circumstances. That said, there are some core guidelines that can help to ensure that good communication and engagement is taking place between airports and their community stakeholders. In the Table below we set out a range of recommendations that airports should consider when looking to conduct 'IDEAL' communication and engagement with residents. One should also note however that as a two-way process, communication and engagement is not necessarily in the hands of airports in its totality. Communities too have a responsibility to engage with airports about noise, to learn about noise management and to understand noise data made available to them. That said, it has to be stressed that as the source of the noise, and with the agency to make change, it is airports who must play the lead role in facilitating engagement and in providing information that is both relevant to residents and that is produced in a way that is comprehensible to non-experts.

The 'IDEAL' characteristics of communication and engagement

\begin{tabular}{|c|c|}
\hline \multirow[t]{4}{*}{ I } & $\begin{array}{l}\text { Inclusive and diverse: No communities or hard to reach groups should be left behind. } \\
\text { This can include those who do not have a history of complaints, and those in deprived } \\
\text { areas or those consisting of different nationalities }\end{array}$ \\
\hline & $\begin{array}{l}\text { Information provision: Residents should be provided with data relevant to them. This } \\
\text { means taking the time to understand what those data are, how they can be illustrated or } \\
\text { described, and what appropriate communication channels might be }\end{array}$ \\
\hline & $\begin{array}{l}\text { Impartial: Advanced communication and engagement is not an easy task as it can } \\
\text { involve having difficult conversations with conflicting voices. Independent facilitation } \\
\text { can help overcome these challenges whilst also providing access to experts in the } \\
\text { facilitation of things like focus groups and workshops. Data provided by impartial } \\
\text { experts can also help to build trust }\end{array}$ \\
\hline & $\begin{array}{l}\text { Interrogate: It is important to ask questions about any pre-held perceptions about noise } \\
\text { problems and their likely solutions as what may appear to be a challenge to be solved } \\
\text { (i.e. reducing complaints), may actually be triggered by something at a deeper level. } \\
\text { Questioning such perceptions and gaining insight from residents can be a useful way } \\
\text { to understand how core challenges can be addressed, to identify targeted outcomes, } \\
\text { and to establish potential criteria on which such outcomes can be evaluated }\end{array}$ \\
\hline \multirow[t]{2}{*}{$\mathrm{D}$} & $\begin{array}{l}\text { Decisions: All stakeholders may have expert knowledge that has the potential to } \\
\text { inform decision making, or to influence the potential success of a given intervention. It } \\
\text { can be helpful therefore to perform stakeholder analysis or stakeholder mapping when } \\
\text { performing any activities that are likely to influence noise to identify two factors: who } \\
\text { has interest in the issue, and who can have influence over the issue. With this } \\
\text { information it is possible to determine who should be engaged about noise-although } \\
\text { it should be considered that sometimes there can be unintended consequences that } \\
\text { could affect groups that were not expected. It can therefore be helpful to include all } \\
\text { groups in engagements in order to develop well rounded understanding and to aid } \\
\text { decision making }\end{array}$ \\
\hline & $\begin{array}{l}\text { Direct: Airports should be honest with the citizens. This means that airports should } \\
\text { start communicating honestly, directly and transparently from the beginning of a } \\
\text { decision process }\end{array}$ \\
\hline
\end{tabular}


(continued)

The 'IDEAL' characteristics of communication and engagement

\begin{tabular}{l|l}
\hline E & Early: Communities should be communicated with early and often throughout any
\end{tabular} changes that may affect them. This is important to make them aware of what is happening, but also to understand their needs, preferences, fears and so on, and to communicate any potential changes to the noise they may be exposed to (be it on a trial or temporary basis)

Easy: It is important that data is communicated and explained as clearly as possible and that information is easy to understand without any previous knowledge or expertise.

Presenting complex information that people find difficult to grasp can lead to airports being accused of hiding data by purposely putting up barriers. Communication and engagement should be tailored to the characteristics of each airport and community groups and what the interaction sets out to achieve. This includes using appropriate language and data, both in terms of relevance to the subject of the communication or engagement, but also to the expertise and comprehension of the recipient

Explain: Airports should not just be explaining what has happened and what the results of any changes have been. They should also articulate, clearly, why decisions have been made, whether other options were considered, why other options may not have been selected. Noise action plans can be a great way to demonstrate that noise has been addressed at a strategic level

Empathy: Effective communication and engagement means going beyond numbers and thinking in qualitative terms by developing stories of the lived experiences of residents and developing and acknowledging empathy for those stories. Airports can also tell their own stories to help articulate the significant difficulties that they have in managing noise, thus helping to foster empathy for their own situation

A Accessible: Information should be easy to find and not hidden in technical reports, or multiple clicks into a website. For communication to be received effectively its intended audience should be able to access that information as easily as possible. Hard to find information gives the impression of mis-intent, which can be harmful to trust in airport-stakeholder relationships

Authentic: Communication that does not set out to convey a certain message or have some intended outcome should generally be avoided as it can be considered as communication for communication's sake. Rather any communication should have some targeted outcome or rationale for taking place. Meanwhile engagement should be based on concepts of empowerment, trust and learning-engagement without these factors is less likely to lead to socially-optimal outcomes

Accurate: It is easy to begin any decision-making process with perceptions of the challenge and any likely solutions. It is no different for noise. What can be perceived by an airport to be an issue that needs to be solved by obvious operational solutions may not actually be the core issue that needs to be addressed. For instance, setting out merely to reduce complaints is not likely to be as effective as setting out to solve the 'triggers' to those complaints. Management interventions that seek to address challenges without going to these deeper levels can result in money and time being wasted, or worse - damaging a situation yet further. It can be important to spend time listening and speaking to stakeholders to try to better understand a given noise problem

Amenable: If decisions are made that are wrong from the citizens' point of view or there is new knowledge, then there are possibilities to amend these decisions 
(continued)

The 'IDEAL' characteristics of communication and engagement

\begin{tabular}{l|l}
\hline L & Legitimacy: We all have our own internal maps about what the world looks like, and to
\end{tabular} each of us those maps are reality. It is important to respect those views. Treating stakeholders and their views with respect and dignity is important in building trust and building effective relationships with residents and campaign groups

\section{Vienna Airport: Now an Example of Good Communication and Engagement}

Following from the opposition campaigns that resulted from the third runway announcement, in 2001 the airport embarked on a formal mediation process with all their stakeholders in an attempt to heal the wounds from the conflict surrounding the third runway and to build a better relationship across all stakeholders. The mediation group counted as many as 50 parties including air traffic control, airlines, mayors from communities, and communities themselves.

The mediation process concluded in 2005 with two key outcomes. First, a mediation contract was established which agreed to put in place a number of noise regulations and limits to protect local communities, whilst acknowledging the importance of the airport to the local economy. It also saw a creation of an environmental fund for breaches of noise limits to be channelled back into community projects. These achievements were made possible because of an acknowledgement on the side of industry that they had a responsibility to protect communities from noise, whilst community groups also acknowledged the importance of airport growth to the local economy. This created a shared vision on which all parties could build.

Second, the group founded a Dialogue Forum with the purpose of handling issues and conflicts related to flight operations and to develop solutions to any conflicts of interest that may arise. The Forum comprises members of all stakeholders, including from all communities around the airport. All communities are included on any issues that are discussed, even if they are not directly impacted, with the aim of promoting fairness, whilst helping to ensure that unpredicted impacts could be accounted for. The group meets regularly and are independently chaired away from the airport to help to ensure accountability and levelled hierarchies of control. Meanwhile a member of AustroControl (the Austrian air navigation services provider) also sits on the forum and provides data for residents as requested, also explaining results to them, and thus helping to build trust and confidence in the data provided. To date, the airport has not implemented any major changes without prior approval from the Dialogue Forum, and the process has proved robust enough to mean that there have been no rejections of any management proposals made to date. 


\section{Evaluation}

Evaluation is a vital instrument to assess, validate and rate the success of an communication, engagement or other noise management measure during the whole process of forming, implementing, and postprocessing an intervention, helping to keep track of each step of the process of implementation and to reflect on the process and derive implications for beneficial adjustments. Further, evaluation helps to assess intended and unintended outcomes and the impact the intervention has on the target group and its effectiveness in terms of cost-benefit analysis.

Fundamental aspects of an evaluation include defining the aim of an intervention (i.e. what do we want to achieve with the intervention), definition of a target group (i.e. who is to be addressed and/or involved), definition of success criteria (e.g. when is an intervention considered as successful-with decrease of complaints, with a measurable increase in Quality of Life or a measurable increase in perceived fairness?), defining the way of proceeding to achieve the goals as well as how to come to an agreement on the procedure of engagement. These aspects of evaluation should be defined in advance.

During the implementation process it is favourable to monitor the implementation according to definition criteria, e.g. is this the right target group? Are people responding as anticipated to the intervention? What preliminary outcomes are observed, both intended and unintended? Is there a need for fine-tuning?

The impact assessment is conducted after the intervention has been implemented. Corresponding to the success criteria it is to be assessed what has been achieved regarding the defined outcome. Was the engagement process carried out as outlined at the beginning of the process? The fairness questionnaire developed within ANIMA project can be a useful instrument to assess/evaluate the process of the implementation of an intervention and the intervention itself.

Results from the evaluation process can be used to tailor future interventions to the characteristics of an airport region and/or to adapt and thus improve already implemented interventions.

\section{Evaluating Fairness in the Context of Aircraft Noise Management-Introduction of an Psychometric Instrument}

Since fairness is considered to be a highly important part of effective communication and engagement a psychometric questionnaire has been developed in the framework of ANIMA.

Based on the latest research in the field of justice psychology and in accordance with findings that have emerged in the exchange with affected citizens, a psychometric questionnaire was developed by conducting a study in the proximity of various German airports. This questionnaire is able to empirically capture the quality and success of airport management strategies via focusing on the perceived procedural, 
informational and interpersonal aspects of the residents' perception of the airport management's actions. In summary, the questionnaire is able to capture the perception of a fair and neighbourly relationship.

Since different aspects of fairness are captured in a differentiated manner, concrete statements can be made on whether interventions that are intended to address certain aspects of neighbourliness (e.g. more involvement of citizens, comprehensible information provision) are also perceived as such.

With the survey of aspects of neighbourliness, not only can the effectiveness of interventions be assessed, but it can also be determined at which points an intervention is necessary at all. Thus, the questionnaire offers an empirical instrument that can be used in a versatile and economical way due to its proven psychometric quality.

\section{ANIMA in Action}

The ANIMA Project has approached noise on a theoretical and practical level, by conducting research to help understand and inform on future communication and engagement practice, but also by working directly with airports to disseminate what we have learned. Below, we present one such case study, carried out in collaboration between ANIMA researchers and Rotterdam The Hague Airport.

\section{Rotterdam the Hague}

Rotterdam The Hague Airport is a regional airport near the city of Rotterdam, with a maximum capacity of just over 50 thousand flights a year [28, 29]. It has one paved runway and it features mostly holiday traffic, general aviation flights and helicopter movements. Due to the location of the airport in the vicinity of the city of Rotterdam and surrounding villages, noise annoyance is an issue. A regional consultation committee, called "Commissie Regionaal Overleg" (CRO), deals with matters related to noise annoyance by aviation. The CRO consists of representatives of the airport, local government, and community representatives.

A project group consisting of representatives from the airport, the community, the local ANSP, experts and the NLR was formed to investigate the benefits of optimising the runway 06 take-off procedure. The aim is to reduce the overall aircraft noise annoyance. According to calculations of noise contours including $\mathrm{L}_{\mathrm{den}}$ and $\mathrm{L}_{\mathrm{Amax}}$ noise levels, a reduction in noise exposure for some areas was expected by adjusting the initial turn of the departure procedure. Overall the noise exposure would be shifted. This means that some regions initially exposed to higher noise levels would benefit with the alternative departure procedure. However, other regions which are initially exposed to lower noise levels would receive higher noise levels.

There is no secondary goal for this operational change, such as capacity increase or reduction of fuel. Therefore, the opinion of the community is leading in the final 
decision on accepting the alternative departure procedure or not. Due to the complex situation, NLR was asked to investigate the possible impact of this operational change for the whole community.

Within this study several challenges were discovered. It was difficult to explain the calculated noise levels to the community. Therefore, a simulation was set up to compare the aircraft noise between the original and the alternative procedure for five different locations around the airport.

For each location, the current and the alternative flyover sounds were played, and subsequently, they were intermittent played (with $4 \mathrm{~s}$ interval) for direct comparison. The locations were discussed within the initial project group. Five representative locations along the flight path that were the most and the least impacted were chosen for the simulations. The simulation was first tested by people from the $\mathrm{CRO}$, and after that, evaluated by 15 people recruited by the community representatives. The key provision in the set-up is that the locations that were used were not known beforehand, and it was also not known which procedure was the original or the alternative one.

Results from the simulation will be gathered and presented to the community, together with the disclosure of the locations belonging to the evaluated fly-overs. Results should help to evaluate which changes in noise level are audible, and put them in relation to the noise report on this measure. It may also provide directions for future optimisations to address whether they may benefit the community or not. Key learning from this study are related to the community engagement strategy, the structure of the process, the way the information was presented, the feedback from the community and the evaluation on how perceptual data can be used next to traditionally applied calculations to form a fair decision-making process.

\section{Closing Remark}

This chapter has outlined the importance of communication and engagement and set out some core principles that can aid airports in improving speaking to, and listening to, their communities.

It is important that airports engage with citizens more effectively, throughout the entire process of developing and delivering an intervention in order to increase the potential for noise management interventions being successful. It is vital that stakeholders are communicated to and engaged with throughout the process of intervention development if we aspire to develop outcomes that are more likely to be deemed acceptable by all stakeholders.

This can be daunting for airport management who may come from more technical backgrounds and may lack the experience or expertise in qualitative forms of data capture, dissemination and decision making. However, such difficulties will not be resolved by inaction, but by being embraced and embedded in approaches to noise impact management. 


\section{References}

1. Asensio C, Gasco L, de Arcas G (2017) A review of non-acoustic measures to handle community response to noise around Airports. Curr Pollut Rep 3(3):230-244. https://doi.org/10.1007/s40 726-017-0060-x

2. Crichton F, Chapman S, Cundy T, Petrie KJ (2014) The link between health complaints and wind turbines: support for the nocebo expectations hypothesis. Frontiers in Public Health 220(2):1-8. https://doi.org/10.3389/fpubh.2014.00220

3. Bröer C (2006) Policy annoyance how policy discourses shape the experience of aircraft sound (Dissertation). Publisher Aksant, Amsterdam

4. Bröer C (2008) Private trouble, policy issue: people's noise annoyance and policy discourse. Critical Policy Analysis 2(2):93-117

5. Benedetti F, Lanotte M, Lopiano L, Colloca L (2007) When words are painful: unraveling the mechanisms of the nocebo effect. Neuroscience 147:260-271. https://doi.org/10.1016/j.neuros cience.2007.02.020

6. Crichton F, Dodd G, Schmid G, Gamble G, Cundy T, Petrie KJ (2014) The power of positive and negative expectations to influence reported symptoms and mood during exposure to wind farm sound. Health Psychol 33(12):1588-1592. https://doi.org/10.1037/hea0000037

7. Crichton F, Dodd G, Schmid G, Petrie KJ (2015) Framing sound: using expectations to reduce environmental noise annoyance. Environ Res 142:609-614. https://doi.org/10.1016/j.envres. 2015.08.016

8. Cialdini RB, Kallgren CA, Reno RR (1991) A focus theory of normative conduct: a theoretical refinement and reevaluation of the role of norms in human behaviour. In: Zanna MP (ed) Advances in experimental social psychology, vol 24. Academic Press, San Diego, CA, pp 201-234

9. Guski R, Schreckenberg D, Schuemer R (2017) WHO environmental noise guidelines for the European Region: a systematic review on environmental noise and annoyance. Int J Environ Res Public Health 14(12):1539. https://doi.org/10.3390/ijerph14121539

10. Stallen PJM (1999) A theoretical framework for environmental noise annoyance. Noise Health 1(3):69-79

11. Leventhal GS (1980) What should be done with equity theory? In: Social exchange. Springer, pp 27-55

12. Lind EA, Tyler T (1988) The social psychology of procedural justice. Springer Science \& Business Media

13. Thibaut J, Walker L (1975) Procedural justice: a psychological analysis. L. Erlbaum Associates

14. Tyler T, Lind EA (1992) A relational model of authority in groups. In: Advances in experimental social psychology, Vol 25. Elsevier, pp 115-191

15. Maris E, Stallen PJM, Steensma H, Vermunt R (2006) (Un) sound management. Three laboratory experiments on the effects of social non-acoustical determinants of noise annoyance. Paper presented at the INTER-NOISE and NOISE-CON Congress and Conference Proceedings

16. Liebe U, Preisendörfer P, Enzler HB (2020) The social acceptance of airport expansion scenarios: a factorial survey experiment. Transp Res D Transp Environ Planning A 84:102363

17. Bies RJ, Moag JS (1986) Interactional communication criteria of fairness. Res Org Behav 9:289-319

18. Bies RJ, Shapiro DL (1987) Interactional fairness judgments: the influence of causal accounts. Soc Justice Res 1(2):199-218

19. Bies RJ, Shapiro DL (1988) Voice and justification: their influence on procedural fairness judgments. Acad Manag J 31(3):676-685

20. Adams JS (1965) Inequity in social exchange. In: Advances in experimental social psychology Vol 2. Elsevier, pp 267-299

21. Leventhal GS (1976) The distribution of rewards and resources in groups and organisations. Adv Exp Soc Psychol 9:91-131

22. Bartels S (2014) Aircraft noise-induced annoyance in the vicinity of Cologne/Bonn Airport-The examination of short-term and long-term annoyance as well as their major determinants 
23. Hooper P, Flindell I (2013) Exchanging aircraft noise information with local communities around airports: the devil is in the detail. In: 42nd international congress and exposition on noise control engineering 2013, INTER-NOISE 2013: Noise Control for Quality of Life

24. Directive 2002/49/EC of the European Parliament and of the Council of 25 June 2002 relating to the assessment and management of environmental noise. Official Journal of the European Communities 18.7.2002; L189/12

25. CAA (2021) Airspace Change. Guidance on the regulatory process for changing the notified airspace design and planned and permanent redistribution of air traffic, and on providing airspace information. CAP 1616. Civil Aviation Authority. March 2021. 4th edn. Available on-line: Guidance on the regulatory process for changing the notified airspace design and planned and permanent redistribution of air traffic, and on providing airspace information. CAP 1616. Available at: https://publicapps.caa.co.uk/docs/33/CAA_Airspace\%20Change\%20Doc_ Mar2021.pdf (Accessed: 30 March 2021).

26. FAA (2015) Fact Sheet-The FAA Airport Noise Program. Federal Aviation Authority. Available at: https//https://www.faa.gov/news/fact_sheets/news_story.cfm?newsId=18114. Accessed 30 March 2021

27. Arnstein SR (1969) A Ladder of Citizen participation. J Am Inst Plann 35(4):216-224. https:// doi.org/10.1080/01944366908977225

28. EHR -ROTTERDAM/Rotterdam (2021) AIP from AIS the Netherlands, effective 25 February 2021. On-line. https://www.lvnl.nl/eaip/2021-01-14-AIRAC/html/eAIP/EH-AD-2.EHRD-enGB.html. Accessed 30 March 2021

29. Rotterdam The Hague Airport (2021) Annual Statistics 2010-2019. https://www.rotterdamthe hagueairport.nl/content/uploads/2020/01/Totaal-per-jaar-januari-2020.pdf. Accessed $17 \mathrm{Mar}$ 2021

Open Access This chapter is licensed under the terms of the Creative Commons Attribution 4.0 International License (http://creativecommons.org/licenses/by/4.0/), which permits use, sharing, adaptation, distribution and reproduction in any medium or format, as long as you give appropriate credit to the original author(s) and the source, provide a link to the Creative Commons license and indicate if changes were made.

The images or other third party material in this chapter are included in the chapter's Creative Commons license, unless indicated otherwise in a credit line to the material. If material is not included in the chapter's Creative Commons license and your intended use is not permitted by statutory regulation or exceeds the permitted use, you will need to obtain permission directly from the copyright holder.

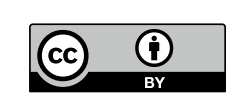

